conjugation, and accomodation probably contributed little to the present results since the experimental room was darkened and the visual cues necessary for these mechanisms to function normally were absent. The results most likely are attributable to macular development, which continues through the 4th month of life (Walsh, 1957) and changes in refractive error. Infants are usually hypermetropic (farsighted) at birth since the eyeball is too short for the focal length of the optical mechanisms of the eye; hypermetropia usually decreases with age as the eyeball increases in size (Duke-Elder, 1963). Evidence has been offered that the mean refractive error of newborns is 1.5 diopters (Hershenson, 1967). We have offered evidence that at least 5 diopters of refractive error would be required to account for the effects of check size on VER amplitude in this study at the age of 1 month. This suggests that the apparent improvement in visual acuity with age was primarily due to macular development.

In conclusion, these results indicate that VERs to patterned light flashes give valuable information about the development of mechanisms influencing pattern vision in the human infant. Additional investigations will be required to determine the generality of these data and whether or not they are attributable to the development of mechanisms underlying visual acuity as proposed in this study.

\section{REFERENCES}

$B E R L Y N E, D . E$. The influence of the albedo and complexity of stimuli on visual fixation in the human infant. British Journal of Psychology, 1958, 49, 315-318.

BRIENNAN, W, M., AMIE, E. W., \& MOORE, R. $W$. Age differences in infants' attention to patterns of different complexity. Science, $1966.151,354-356$.

DUKE-LLDER, S. Sy'stems of ophthalmology. Vol. III. Normal and abnormal development Part 1: Embryology. St. Louis: Mosby, 1963. P. 312 .

ELLINGSON, R. J. Cortical electrical responses to visual stimulation in the human infant. Electrocncephalography \& Clinical Neurophysiology, 1960, 12, 663-677.

ELLINGSON, R. J. Studies of the electrical activity of the developing human brain. In $W$. A. Himwich and H. E. Himwich (Eds.), Progress in brain research. Vol. 9. The developing brain. New York: Elsevier, 1964. Pp. 26-53.

IENGEL, R. Electroencephalographic responses to sound and to light in premature and full-term neonates. Lancet, $1967,87,181-186$.

ENGEL, R., \& BENSON, R. C. Estimate of conceptional age by evoked response activity. Biologia Neonatorum, 1968, 12, 201-213.

I:ANTZ, R. L.. ORDY, J. M.. \& UDELI. M. S. Maturation of pattern vision in infants during the first six months. Journal of Comparative \& Physiological Psychology, 1962, 55, 907-917.

IERRISS, G. S., DAVIS, G. D., DORSEN, M. Mcl.. \& HACKETT, F. R. Changes in latency and form of the photically induced average cvoked response in human infants I Icctroencephalography \& Clinical Neurophysiology, 1967, 22, 305-312.

GORMAN, J. J., GOGEN, D. G., \& GELLIS, S. $S$. Testing the visual acuity of infants, In $Y$. Brackbili and G. G. Thompson (Eds.), Behavior in infancy and early childhood. New York: The Free Press, 1967. Pp. 173-178.

HARTER, M. R., \& WHITE, C. T. Effects of contour sharpness and check-size on visually evoked cortical potentials. Vision Research, $1968,8,701-711$.

HARTER, M. R., \& WHITE, C. T. Evoked cortical responses to checkerboard patterns: Effects of check-size as a function of visual acuity. Electroencephalography \& Clinical Neurophysiology, $1969,28,48-54$.

HERSHENSON, M, Development of the perception of form. Psychological Bulletin. $1967,67,326-336$.

HRBEK, A., VITOVA, Z., \& MARES, P. The development of cortical evoked responses to visual stimulation during childhood. Activitas Nervosa, 1966, 8, 39-46.

KARMEL, B. Z. The effects of age, complexity, and amount of contour on pattern preferences in human infants. Journal of Experimental Child Psychology, 1969, 7, 339-354.

RIETVELD, W. J., TORDOIR, W. E.,
HAGINOUW, J. R., LUBBERS, J. A., * SPOOR, Th. A. Visual evoked response to blank and to checkerboard patterned flashes. Acta Physiologica \& Pharmacologica Neerlandia, 1967, 14, 259-285.

SPEHLMANN, $R$. The averaged electrical responses to diffuse and to patterned light in the human. Electroencephalography \& Clinical Neurophysiology, $1965,19,560-569$.

WALSH, F. B. Neuro-ophthalmology. Baltimore: Williams \& Wilkins, 1957. P. 348.

\section{NOTES}

1. This research was supported by funds received from the National Science Foundation under Grants GB-8053 and GB-7324 and from a University of North Carolina institutional grant. Our idea of using VERs to study pattern vision in infants was originally conceptualized with Bernard Z. Karmel and Carroll $T$. White at the Naval Electronics Laboratory Center, San Diego, California. We thank Susan A. Harter, the mother of our subject, for her help in conducting this study.

2. Harter, M. R. Evoked cortical potential correlates of visual acuity and pattern perception in humans. Presented at Southeastern Psychological Association, 1969 (in preparation for publication).

\title{
Catecholamine excretion as a function of
}

\section{personality ${ }^{1}$}

HARTMUT SCHULZ and HANS STROBACH, Psychological Institute and Pharmacological Institute, University of Düsseldorf, West Germany

An experiment was designed to study the relationship between urine catecholamine excretion and the personality traits of extraversion and neuroticism. Using chance samples of day-urine, we found a significant negative correlation between extraversion and the amount of urine catecholamines. This relationship is modified by smoking habits. The correlation holds only for nonsmokers.

Although it is well established that excretion rates of adrenaline (A) and noradrenaline (NA) are strongly influenced by stressful situational factors and by momentary affective states (Levi, 1967; Schildkraut \& Kety, 1967), there is no good evidence of a correlation with stable, transituational personality traits (Mason, 1968).

Here we show a relationship between catecholamine excretion and extraversion-introversion (E) and neuroticism-stability $(\mathrm{N})$ as measured by the Maudsley Personality Inventory, or MPI (Eysenck, 1959).
On Eysenck's hypothesis, that extraversion is associated with low and unspecific cortical atousal by pathways from the reticular formation (Eysenck, 1967), we assumed that it also would be associated with a low level of peripheral catecholamines, which regulate blood pressure. The linkage is given by experiments that show that the activity of the cells of the reticular formation depends on arterial blood pressure (Baust et al, 1963). The MPI was also used in two other studies of catecholamine output (Levi, 1963; Fine \& Sweeney, 1968), but the results are not clear. Levi (1963), who used peer ratings and MPI scores, presumably on the $\mathbf{N}$ scale, for selecting groups of high and low emotional resistance, did not give any data on the relationship between MPI scores and the excretion of catecholamines. Fine and Sweeney, who tested 27 soldiers under different experimental settings in a 3-day experiment, found a positive relation between MPI-N and the noradrenaline-adrenaline (NA/A) ratio, but the meaning of the ratio (as will be shown later on) is in doubt. They found no significant relation between MPI-E and catecholamine excretion, perhaps because they used 24-h samples instead of day-urine only. 
Table 1

Product Moment Correlations Between MPI Extraversion (E), Neuroticism (N) and Adrenaline (A), Noradrenaline (NA), and NA + A for the Entire Group and the Subgroups of Smokers and Nonsmokers

\begin{tabular}{|c|c|c|c|c|c|}
\hline Group & $\mathrm{n}$ & MPI & A & $\mathrm{NA}$ & $\mathrm{NA}+\mathrm{A}$ \\
\hline Entire Group & 54 & $\begin{array}{l}E \\
N\end{array}$ & $\begin{array}{l}-.14 \\
-.21\end{array}$ & $\begin{array}{l}-.33^{*} \\
-.03\end{array}$ & $\begin{array}{l}-.34^{*} \\
-.09\end{array}$ \\
\hline Smokers & 27 & $\begin{array}{l}\mathbf{E} \\
\mathbf{N}\end{array}$ & $\begin{array}{l}.03 \\
.19\end{array}$ & $\begin{array}{r}.05 \\
-.12\end{array}$ & $\begin{array}{r}.05 \\
-.05\end{array}$ \\
\hline Nonsmokers & 15 & $\begin{array}{l}\mathrm{E} \\
\mathrm{N}\end{array}$ & $\begin{array}{r}.06 \\
-.40\end{array}$ & $\begin{array}{c}-.57^{*} \\
.21\end{array}$ & $\begin{array}{c}-.52 * \\
.08\end{array}$ \\
\hline
\end{tabular}

$* p<0.05$ (two-tailed)

\section{METHODS}

In the present experiment, urine samples and MPI data were collected from 54 men, mostly medical students, whose ages ranged from 19 to 31 years. The means as well as the standard deviations of the MPI scores of the group are quite close to those reported for American students (Eysenck, 1959). The urine samples were collected between noon and 3 p.m. No restrictions were imposed with regard to eating, smoking, or other activities of the Ss prior to the urine sampling, although smoking habits and recent intake of drugs were registered for control purposes. Catecholamine values were measured by a fluorimetric technique (Euler \& Lishajko, 1961) modified by the second author. The reliability of the biochemical determinations was assessed by double analysis of 15 of the urine samples. The reliability coefficients were: $r=0.83$ for $A$ and $\mathrm{r}=0.86$ for NA.

\section{RESULTS AND DISCUSSION}

Correlational analysis was used also to study the relationship between the biochemical and personality scores. As shown in Table 1, significant negative correlations were found between extraversion and NA $(r=-0.33, p<0.05)$ and between extraversion and $\mathrm{NA}+\mathrm{A}$ $(\mathrm{r}=-0.34, \mathrm{p}<0.05)$. There was no significant relation between catecholamines and neuroticism, as measured by the MPI. Because there are some indications in the literature that cigarette smoking may influence the catecholamine level (Watts \& Bragg, 1956; Frankenhaeuser et al, 1968), the Ss were grouped according to their smoking habits.

After pipe smokers and Ss from whom data on their smoking habits were missing were eliminated, there remained 27

Table 2

Product Moment Correlations Between MPI Extraversion (E), Neuroticism (N) and the Ratios NA/A and $A / N A$

\begin{tabular}{|c|c|c|c|c|c|}
\hline \multirow[b]{2}{*}{ Group } & \multirow[b]{2}{*}{$\pi$} & \multicolumn{2}{|c|}{ NA/A Ratio } & \multicolumn{2}{|c|}{ A/NA Ratio } \\
\hline & & $\mathbf{E}$ & $\mathrm{N}$ & $\mathbf{E}$ & $\mathbf{N}$ \\
\hline Entirc Group & 54 & -.27 & $.32^{*}$ & .04 & -.04 \\
\hline Smokers & 27 & .09 & -.22 & .00 & .02 \\
\hline Nonsmokers & 15 & $-.53^{*}$ & $.78 * *$ & .24 & -.35 \\
\hline
\end{tabular}

* $p<0.05$ (two-tailed)

** $p<0.01$ (two-tailed) which would be also distorted, simply do not occur, because the $\mathrm{NA}$ output normally is greater than the A output. Using the NA/A ratio, we found some significant correlations with the personality traits, but there were none with the $A / N A$ ratio (see Table 2 ).

This study, which is just a beginning, reveals some relationship between catecholamine output and personality. The correlations are not very large, and they are influenced by moderator variables (Ghiselli, 1963), but the results are in agreement with Eysenck's theory, that introverts have a higher arousal state than do extraverts.

\section{REFERENCES}

BAUST, W., NIEMCYSK, H, \& VIETH, J. The action of blood pressure on the ascending reticular activating system with special reference to adrenaline-induced EEG arousal. Electroencephalography \& Clinical Neurophysiology, 1963, 15, 63-72.

EULER, U. S., \& LISHAJKO, F. Improved technique for the fluorimetric estimation of catecholamines. Acta Physiologica Scandinavica, 1961, 51, 348-356.

EYSENCK, H. J. Das "Maudsley Personality Inventory. "Göttingen: Hogrefe, 1959.

EYSENCK, H. J. The biological basis of personality. Springfield, 1ll: Charles C Thomas, 1967.

Aside from simple measures of $A$ and NA, the NA/A ratio sometimes is used for analysis. Fine and Sweeney remark that "a ratio which represents the balance between the two humors would be better for comparing individuals than would absolute levels [1967, p. 14]." This ratio is of some interest because it may represent a measure of ergotropic/trophotropic balance (Gellhorn, 1965). Unfortunately, however, the NA/A ratio has some properties that may reduce its value for statistical purposes because the ratio increases progressively when $\mathbf{A}$ decreases, and if $\mathbf{A}$ approaches zero, the ratio approaches infinity. With increasing values for $A$, the ratio approaches zero. This distorting effect of the ratio becomes even more troublesome if one keeps in mind that the biochemical analysis of small fractions of $A$ is not very reliable. Errors arising from the biochemical analysis therefore will be potentiated by the NA/A ratio. It seems better to use the inverse ratio, $\mathbf{A} / \mathbf{N A}$, for quantitative studies because it tends to minimize such errors. A/NA ratios $>2.0$,

INE, B. J., \& SWEENEY, D. R. Socio-economic background, aggression and catecholamine excretion. Psychological Renorts, 1967, 20, 11-18.

FINE, B. J., \& SWEENEY, D. R. Personality traits and situational factors, and catecholamine excrction. Journal of Experimental Research in Personality, 1968, 3, 15-27.

FRANKENHAEUSER, M., MYRSTEN, A.-L., WASZAK, M., NERI, A., \& POST, B. Dosage and time effects of cigarette smoking. Report from the Psychological Laboratories, University of Stockholm, No. 248, 1968.

GELLHORN, E. The neurophysiological basis of anxiety: A hypothesis. Perspcctives in Biology \& Medicine, 1965, 8, 488-5 I5.

GHISELLI, E. E. Moderating effects and differential reliability and validity. Joumal of Applied Psychology, 1963, 47, 81-86.

LEVI, L. The urinary output of adrenalin and noradrenalin during experimentally induced emotional stress in clinically different groups. Acta Psychotherapeutica, 1963, 11, 218-227. LEVI, L. Sympatho-adrenomedullary responses to emotional stimuli: Methodologic, physiologic and pathologic considerations. In E. Bajusz (Ed.), An introduction to clinical neuroendocrinology. Basel/New York: Karger, 1967. Pp. 78-105.

MASON, J. W. A review of psychoendocrine research on the sympathetic-adrenal medullary system. Psychosomatic Medicine, 1968, 30 , $631-653$.

SCHILDKRAUT, J. J., \& KETY, S. S. Biogenic amines and emotions. Science, 1967, 156, 21-30.

WATTS, D. T., \& BRAGG, A. E. Effect of smoking on the urinary output of epinephrine and norepinephrine in man. Journal of Applied Physiology, 1956, 9, 275-278. NOTE

1. The authors are indebted to Prof. M.E. Bitterman and Dipl.-Psych. H. Meyer-Bahlburg for their valuable suggestions. 